\title{
The Lipodystrophy Syndrome as a Risk Marker for Cardiovascular Disease in Patients with HIVIAIDS Treated with HAART
}

\section{Abstract}

Introduction: The classic risk factors for cardiovascular disease in healthy individuals are well known, however, it lacks in the literature the mechanisms that predicts cardiovascular disease in the population living with HIV-AIDS treated with HAART and presenting syndrome lipodystrophy. We aimed to investigate the risk of cardiovascular disease in HIV-AIDS patients treated with HAART and lipodystrophy syndrome.

Methods: A search was performed in Medline, SciELO, Lilacs and Cochrane using the intersection between the keywords: "cardiovascular disease", "HIV", "AIDS", "HAART" and "lipodystrophy syndrome".

Results: The selected studies demonstrated that metabolic disorders such as hyperlipidemia, central adipose hypertrophy and peripheral lipoatrophy, besides the metabolic syndrome and lipodystrophy are maker clear risks of developing cardiovascular disease in these individuals.

Conclusion: The metabolic alterations in HIV-AIDS treated with HAART and presenting lipodystrophy syndrome may potentiate the development of cardiovascular diseases.

\section{Keywords}

HIV; Lipodystrophy syndrome; cardiovascular disease; AIDS.
Valdelias Xavier Pereira ${ }^{1,2}$, Luiz Carlos de Abreu ${ }^{2}$, Vitor E. Valenti ${ }^{3}$, Rodrigo D. Raimundo², Mariliza Henrique da Silva ${ }^{4}$, Fernando R. Oliveira*1,2, Renata Salatini², Adriano L. Roque ${ }^{1,2}$, Marcia de Toledo Blake², Erick Silva Dias ${ }^{1,2}$, Celso F. Filho', Vivian Finotti ${ }^{1}$, Celso Ferreira ${ }^{1}$

1 Federal University of São Paulo - Paulista School of Medicine - Department of Medicine. São Paulo, SP, Brazil.

2 Laboratory Design and Scientific Writing. Department of Community Health, $A B C$ Medical School. Av Principe de Gales, 821, 09060-650. Santo André, SP, Brazil.

3 Center for the Study of the Autonomic Nervous System, Speech Therapy Department Faculty of Sciences, UNESP, Marília, SP, Brazil.

4 City of São Bernardo do Campo. Coordinator of Outpatient Medical Specialties. São Bernardo do Campo, SP, Brazil.

\section{Contact information:}

巨luiz.abreu@fmabc.br 


\section{Background}

The introduction of antiretroviral therapy in highpower highly active antiretroviral therapy (HAART) has resulted in the reduction of mortality associated with acquired immunodeficiency syndrome (AIDS) in developed countries and in Brazil, despite the increased number of individuals with AIDS in developing countries [1-4].

However, as a result of this treatment, other complications arose, including a metabolic disorder called lipodystrophy syndrome (SLD), which is characterized by changes in body fat distribution (increased waist circumference and breasts, fat accumulation in the neck, jaws especially the cheeks, buttocks) and/or metabolic abnormalities (insulin resistance and dyslipidemia). These changes increase the risk for cardiovascular disease [4, 5].

Individuals infected with immunodeficiency virus $(\mathrm{HIV})$, requiring treatment for decades, leading to cumulative exposure, become more vulnerable to the side effects of antiretroviral drugs. Moreover, drugs used to treat dyslipidemia are not adequately studied in relation to patients who use the HAART drugs. Some of them should be used with caution, because they affect the serum concentration of the antirretroviral drugs [6, 7]. Additonally, the current epidemiological transition shows that a diet rich in saturated fats associated with physical inactivity is a risk factor for cardiovascular diseases $[8,9]$.

\section{Objective}

In this sense, this study aimed to investigate the risks of cardiovascular disease in HIV-AIDS patients treated with HAART and lipodystrophy syndrome.

\section{Method}

\section{Search and selection strategy}

Revisions were made between September 2012 and January 2013. The following database were used:
MEDLINE (via PubMed), SciELO, Lilacs and Cochrane. We used the following keywords: "cardiovascular disease", "HIV", "AIDS" and "lipodystrophy syndrome". The keywords were defined according to the Medical Subject Headings (MeSH).

Studies were selected by one researcher and supervised by a senior researcher. Based on titles and abstracts, the manuscripts not clearly related to the topic were excluded.

Studies that did not show full text or summary in English between 2001 and 2011 and literature reviews were excluded. Inclusion criteria considered clinical trials and basic studies investigating the risk of cardiovascular disease in individuals with HIV/ AIDS. All selected titles and abstracts were submitted to a final review, which considered the inclusion criteria.

\section{Results}

The electronic search yielded a total of 1425 references. Among these references, the first elimination resulted in the exclusion of 1297 titles and abstracts, which were not clearly related to the subject of review. The titles of the remaining 128 abstracts were submitted to a final review, which took into account the inclusion criteria. The investigation of reference lists confirmed the absence of relevant documents. Summaries of the six studies were selected. Table 1 shows the risk of occurrence of cardiovascular diseases, the main results and conclusions of the studies included. (Table1).

\section{Discussion}

The analysis of texts selected for this review indicated that plurimetabolic changes are considered risk factors for developing cardiovascular disease in the population studied. Moreover, the lipodystrophy syndrome behaved as unequivocal marker of risk. The literature also reported how HAART influences the metabolic impairment and as a 
Table 1.

Authors and year

Lomar AV, 2005 [10]

Caron et al., 2003 [15]

Lipid abnormalities found in the lipodystrophy syndrome are increased serum levels of triglycerides (TGC) and/or total cholesterol at the expense of (LDL), with a trend towards decreased levels (HDL).

Galli et al., 2012 [18]

Sutinen et ai., 2012 [19]

(DAD) Study Group, 2011 [23]

Law, 2004 [26]

\section{Main Findings}

HAART has 17 drugs that are divided into 4 classes: (NRTIs) (NNRTI), (IP) (IF).
Among the anatomic changes of fat redistribution, we identify three groups: lipoatrophy, lipohypertrophy and the mixed form.

The incidence of myocardial infarction or any ischemic vascular event increased with longer exposure to HAART.

There is increased risk of developing cardiovascular disease patients with DM, obesity, coinfected with hepatitis C. The author reports $16 \%$ increase in the incidence of myocardial infarction per year of HAART and with Lipo dystrophy syndrome.

consequence increases the risk of cardiovascular alterations.

According to Lomar, HAART has 17 drugs that are divided into 4 classes: reverse transcriptase inhibitors nucleotide analogues (NRTIs), which act on the enzyme reverse transcriptase, incorporating DNA into the virus and creating chain. It induces the defective chain and prevents the virus from reproducing; inhibitors of reverse transcriptase-nucleotide analogues (NNRTIs), which directly block the action of the enzyme, its propagation and development of the infestation in the body; protease inhibitors (PI), which prevents the production of new copies of HIV-infected cells and fusion inhibitors (PI) which prevents the entry of the virus into the cell [10].

Martinez et al, showed that the advent of HAART increases the possibility of viral eradication, but studies have demonstrated the impossibility of complete removal of HIV in the body. In this circumstance, considering the current knowledge, patients with AIDS have to make use of antiretroviral drugs for life, making them indefinitely subjected to the risk of cardiovascular disease. Criteria used for initiating therapy takes into account the patient's clinical sta- tus and CD4 + lymphocytes. The viral load measurement is important for the proper choice of the various schemes available, as well as for monitoring therapeutic outcome, which aims to reduce the viral load to below 50 RNA copies/mL, as measured by the technique of polymerase chain reaction (PCR) or similar [11, 12].

The introduction of antiretroviral therapy has led to increased survival of HIV seropositive patients, however, it is also related to the advent of new and important problems. The authors showed that the redistribution of body fat and metabolic abnormalities, called as lipodystrophy syndrome, are among the most prevalent and worrisome side effects of HAART, besides the high risk of cardiovascular diseases $[12,13,14]$.

Based on Caron et al, lipid abnormalities found in SLD are increased serum levels of triglycerides (TGC) and/or total cholesterol at the expense of low-density lipoprotein and low-density lipoproteins (LDL), with a tendency to decrease levels of high density lipoproteins and high density lipoproteins (HDL) [15].

Hypertriglyceridemia is mainly due to the high rates of de novo lipogenesis and delayed clearance of 
TGC post-prandial period [16]. Studies also revealed that a significantly increased proportion of patients using IP had elevated serum levels of fasting poliprotein $B$ and $E$, possibly by increased synthesis, which could be related to the manifestation of hiperlipidemia16. Furthermore, metabolic syndrome was present in $18 \%$ of HIV patients under HAART treatment, especially in patients using [IP17]. The abnormalities may manifest as glucose intolerance, insulin resistance or diabetes mellitus (DM) $[15,17]$.

Galli and others explain the mechanisms by which antiretroviral (ARV) drugs, such as protease inhibitors, that cause insulin resistance, leading to reduced uptake mediated by insulin in adipocytes and skeletal muscle glucose by interfering with the transmembrane glucose transporters GLUT-4, in addition to the effect transcription factor steroid regulatory element-binding protein 1c (SREBP-1) affecting glucose metabolism to produce imperfect expressions gamma receptor peroxisome proliferator-activated (PPAR-gamma) [18].

It is not yet clear whether the loss of bone mineral density is the same syndrome component [17]. Avascular necrosis has been considered a SLD complication of HIV, since hyperlipidemia and HIV infection are known risk factors for osteonecrosis of femural head [16, 19].

It was described by Sutinen et al. that among the anatomic changes of fat redistribution, it is identified three groups: lipoatrophy, the lipohypertrophy and mixed forms [19]. The lipoatrophy and lipohypertrophy can occur separately or can occur together in the same patient [4, 19]. In lipohypertrophy is observed accumulation of central fat. The fat accumulation can occur in abdomen, neck, back and breasts. The abdomen gets distended appearance and fat tissue is commonly deposited intra-abdominal or between viscera. Increased intra-abdominal pressure may predispose to abdominal hernias that may eventually require surgical correction [15, 18, 19].

It has also been studied accumulation of lipids in the upper trunk, extending to the armpits in males as well as in the anterior cervical region and suprapubic in both sexes $[19,20,21]$.

The increased volume of the breasts in females occurs mainly due to the fat component, it is not associated with glandular hypertrophy. In males, gynecomastia (glandular hypertrophy) or pseudogynecomastia (fat accumulation) may also occur [12, 15, 22].

The lipohypertrophy is more associated with patients with more advanced age at start of treatment, higher body mass index and the use of protease inhibitors [19].

In lipoatrophy there is a loss of peripheral subcutaneous tissue. There is a thinning of the upper and lower limbs, the skin becomes thinned and allows viewing, almost anatomical, of the superficial blood vessels and muscle groups. This picture may give the patient a pseudo-athletic image. Evidence of vascular design is also often confused with (pseudovarices) venous insufficiency [13, 15, 22].

The largest prospective study of cardiovascular risk with HAART is the data collection on adverse events of anti -HIV drugs (DAD) [23]. Among the 23,468 participants, 126 (0.5 percent) had a first myocardial infarction, the incidence was 3.5 per 1000. Among these infarctions, 29 percent were fatal, which is 6 percent of all deaths in the study. There were over 77 events related to coronary ischemia, including artery angioplasty or surgery, ischemic stroke, and carotid endarterectomy [24]. Incidence of myocardial infarction or any ischemic vascular event increased with longer exposure to HAART (relative risk, 1.26 [confidence interval of 95 percent, 1.12 to 1.41] per additional year of exposure, $P<0.001)$. Very few ischemic events occurred to determine the relative risk associated with a specific class of antiretroviral drugs or individual drugs. Hypercholesterolemia, advanced age, smoking, diabetes mellitus, male gender, and a history of cardiovascular disease were also associated with an increased risk of myocardial infarction [23]. Risk of myocardial infarction in relation to duration of 
antiretroviral therapy was significant, but was relatively low in analyzes which adjusted for increased cholesterol levels, suggesting that metabolic abnormalities induced by antiretroviral therapy contributed to increased morbidity observed [23].

Although DAD23 Study Group has found that the relative risk of cardiovascular disease increased with duration of antiretroviral therapy, the absolute risk of cardiovascular disease remain low for most patients, except those with several other cardiovascular risk factors $[25,26]$. The metabolic abnormalities are associated with increased risk of cardiovascular events.

Thus, according to Law et al, HIV positive patients, with significantly higher prevalence of elevated levels of fasting glucose and triglycerides and low HDL cholesterol levels, have increased risk of atherosclerosis, coronary heart disease and diabetes mellitus (DM) $[18,21,26]$. The risk of developing diabetes is 6 to $10 \%$ higher in these patients, and is further increased in obese patients co-infected with hepatitis $C$ virus or virus family history of DM. These authors reported a 16\% increase in the incidence of myocardial infarction per year of antiretroviral therapy $[19,26]$.

\section{Conclusion}

The lipodystrophy syndrome frequently is associated with plurimetabolic changes in individuals with HIV/ AIDS treated with HAART and constitute an important risk marker for cardiovascular involvement of these patients.

\section{Acknowledgement}

This study received financial support from CNPq.

\section{Conflict of interests}

The authors declare no conflicts of interest.

\section{Contributions of authors}

All authors participated in study design, writing and development, besides reviewing the final version of the manuscript. All authors read and approved the final manuscript.

\section{References}

1. Center for Disease Control and Prevention. Pneumocystis pneumonia - Los Angeles. Morbid Mortal Wkly Repor. 1981; 30: $250-2$.

2. Center for Disease Control and Prevention. Kaposi's Sarcoma and Pneumocycstis Pneumonia Among Homosexual Men - New York City and California. Morbid Mortal Wkly Repor. 1981; 30:305-8.

3. Sabino EC, Barreto CC, Sanabani S. AIDS: Etiologia e Subtipos do HIV. In: Veronesi R, Focaccia R, editores. Tratado de infectologia. São Paulo: theneu; 2005. p. 111-7.

4. Soares FMG, and Costa, IMC. Lipoatrofia facial associada ao HIVIAIDS: do advento aos conhecimentos atuais. An. Bras. Dermatol. 2011; p. 843-864.

5. Marques AR, Masur $H$. História Natural da Infecção pelo HIV. In: Veronesi R, Focaccia R, editores científicos. Tratado de infectologia. São Paulo: Atheneu; 2005. p. 143-6.

6. Sadala MLA, Marques AS. Vinte anos de assistência a pessoas vivendo com HIV/aids no Brasil: a perspectiva de profissionais de saúde. Cad Saúde Publ. 2006; 22: 2369-78.

7. Brasil. Ministério da Saúde. Fundação Nacional de Saúde. Guia de Vigilância Epidemiológica. 5. ed. Brasília: Funasa; 20012. 842 p. (Aids/Hepatites Virais; vol. 1).

8. Brasil. Ministério da Saúde. Secretaria de Vigilância em Saúde. Departamento de DST, AIDS e Hepatites Virais. Manual de tratamento da lipoatrofia facial: recomendações para o preenchimento facial com polimetilmetacrilato em portadores de HIVIAIDS. Série A. Normas e Manuais Técnicos. Série Manuais 81. Brasília: Ministério da Saúde; 2009. 44 p.

9. Brasil. Ministério da Saúde. Secretaria de Assistência a Saúde. Programa Nacional de DST/Aids. Consenso sobre a terapia antiretroviral em adultos. Brasília: Ministério da Saúde; 1996.

10. Lomar AV, Diament D. Terapia Anti-retroviral. In: Veronesi R, Focaccia R, editores científicos. Tratado de infectologia. São Paulo: Atheneu; 2005.

11. Martinez E, Mocroft A, García-Viejo MA, Pérez-Cuevas JB, Blanco JL, Mallolas J, et al. Risk of Lipodystrophy in HIV-1infected patients treated with protease inhibitors: a prospective cohort study. Lancet. 2001; 357: 592-8.

12. Piloya $T$ et al. Lipodystrophy among HIV-infected children and adolescents on highly active antiretroviral therapy in Uganda: a cross sectional study. Journal of the International AIDS Society 2012, 15: 17427. 
13. Lenhard JM, Furfine ES, Jain RG, et al. HIV protease inhibitors block adipogenesis and increase lipolysis in vitro. Antiviral Res 2000;47: 121-129.

14. Steven G, and Andrew C. Cardiovascular Risk and Body-Fat Abnormalities in HIV-Infected Adults. N Engl J Med 2005; 352: 48-62.

15. Caron M, Auclair M, Sterlingot H, Kornprobst M, Capeau J. Some HIV protease inhibitors alter lamin A/C maturation and stability, SREBP-1 nuclear localization and adipocyte differentiation. AIDS 2003;17: 2437-2444.

16. Hadigan C, Borgonha S, Rabe J, Young V, Grinspoon S. Increased rates of lipolysis among human immunodeficiency virus-infected men receiving highly active antiretroviral therapy. Metabolism 2010; 51: 1143-1147.

17. Roche R, Poizot-Martin I, Yazidi CM, et al. Effects of antiretroviral drug combinations on the differentiation of adipocytes. AIDS 2012;16: 13-20.

18. Galli M, Veglia F, Angarano G, et al. Gender differences in antiretroviral drug-related adipose tissue alterations: women are at higher risk than men and develop particular lipodystrophy patterns. J Acquir Immune Defic Syndr 2003;34: 58-61.

19. Sutinen J, Hakkinen AM, Westerbacka J, et al. Increased fat accumulation in the liver in HIV-infected patients with antiretroviral therapy-associated lipodystrophy. AIDS 2012;16: 2183-2193.

20. Bozzette SA, Ake CF, Tam HK, Chang SW, Louis TA. Cardiovascular and cerebrovascular events in patients treated for human immunodeficiency virus infection. N Engl J Med 2003; 348: 702-710.

21. Mary-Krause $M$, Cotte $L$, Simon $A$, Partisani $M$, Costagliola $D$. Increased risk of myocardial infarction with duration of protease inhibitor therapy in HIV-infected men. AIDS 2003; 17: 24792486.

22. Currier JS, Taylor A, Boyd F, et al. Coronary heart disease in HIVinfected individuals. J Acquir Immune Defic Syndr 2003; 33: 506-512.

23. The Data Collection on Adverse Events of Anti-HIV Drugs (DAD) Study Group. Combination antiretroviral therapy and the risk of myocardial infarction. N Engl J Med 2003; 349: 1993-2003.

24. d'Arminio A, Sabin CA, Phillips AN, et al. Cardio- and Cerebrovascular Events in HIV-infected Persons. AIDS 2004; 18: 1811-1817.
25. Dressman J, Kincer J, Matveev SV, et al. HIV protease inhibitors promote atherosclerotic lesion formation independent of dyslipidemia by increasing CD36-dependent cholesteryl ester accumulation in macrophages. J Clin Invest 2003; 111: 389397.

26. Law MG, D'Arminio Monforte A, Friis-Moller N, et al. Cardioand cerebrovascular events and predicted rates of myocardial infarction in the D:A:D: study. In: Proceedings of the 11th Conference on Retroviruses and Opportunistic Infections, San Francisco, February 8-11, 2004: 737.

\section{Comment on this article:}

\section{(f) 8 in $8+\mathbf{S} P$}

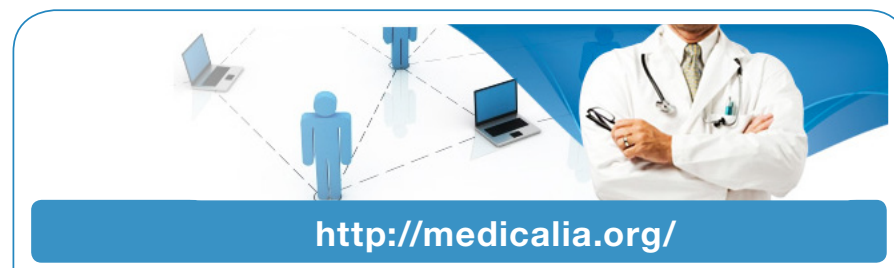

Where Doctors exchange clinical experiences, review their cases and share clinical knowledge. You can also access lots of medical publications for free. Join Now!

\section{Publish with iMedPub}

http://www.imed.pub

International Archives of Medicine is an open access journal publishing articles encompassing all aspects of medical science and clinical practice. IAM is considered a megajournal with independent sections on all areas of medicine. IAM is a really international journal with authors and board members from all around the world. The journal is widely indexed and classified Q1 in category Medicine. 